\title{
HUBUNGAN ANTARA FAKTOR LINGKUNGAN DENGAN PRODUKTIVITAS TAMBAK UNTUK RUMPUT LAUT (Gracilaria verrucosa) DI PANTAI TIMUR PROVINSI SULAWESI SELATAN
}

\author{
Akhmad Mustafa \\ Balai Riset Perikanan Budidaya Air Payau \\ Jl. Makmur Dg. Sitakka No. 129, Maros, Sulawesi Selatan 90512 \\ E-mail: akhmadmustafa@yahoo.com
}

\section{ABSTRAK}

Di pantai timur Provinsi Sulawesi Selatan dijumpai tambak yang lebih luas dibandingkan dengan tambak di pantai barat dan pantai selatan. Tambak di pantai timur Sulawesi Selatan umumnya digunakan untuk budidaya rumput laut (Gracilaria verrucosa) dengan kualitas dan kuantitas produksi yang tergolong tinggi. Informasi mengenai hubungan antara faktor lingkungan tambak (kualitas tanah dan kualitas air) dengan produktivitas tambak untuk budidaya rumput laut di pantai timur Sulawesi Selatan menjadi pokok bahasan dalam tulisan ini. Produktivitas tambak untuk rumput laut di pantai timur Sulawesi Selatan berkisar antara 150 dan 40.909 dengan rata-rata $7.187 \mathrm{~kg}$ kering/ha/tahun. Produktivitas tambak untuk rumput laut yang lebih tinggi di pantai timur Sulawesi Selatan didapatkan pada tanah dengan $\mathrm{pH}_{\mathrm{F}}$ lebih besar 6,5; $\mathrm{pH}_{\text {Fox }}$ lebih besar 4,0; $\mathrm{pH}_{\mathrm{F}}-\mathrm{pH}_{\text {Fox }}$ kurang dari 2,5; dan $\mathrm{S}_{\mathrm{pOS}}$ kurang dari 1,00\% Kandungan Fe tanah yang melebihi 5.000 mg/L dan Al yang melebihi $490 \mathrm{mg} / \mathrm{L}$ menyebabkan penurunan produktivitas tambak untuk rumput laut. Peningkatan kandungan $\mathrm{PO}_{4}$ tanah lebih besar dari $6,0 \mathrm{mg} / \mathrm{L}$ dapat meningkatkan produktivitas tambak untuk rumput laut secara nyata. Produktivitas tambak untuk rumput laut tertinggi didapatkan pada salinitas 25,6 ppt dan oksigen terlarut $8,39 \mathrm{mg} / \mathrm{L}$ dan tumbuh baik pada kisaran pH antara 6,00 dan 9,32 ; suhu antara $26,00^{\circ} \mathrm{C}$ dan $37,86^{\circ} \mathrm{C}$; fosfat lebih besar $0,1000 \mathrm{mg} / \mathrm{L}$; dan besi kurang dari $0,1000 \mathrm{mg} / \mathrm{L}$ di pantai timur Sulawesi Selatan.

KATAKUNCl: faktor lingkungan, tambak, rumput laut, Sulawesi Selatan

\section{PENDAHULUAN}

Secara geografis, tambak di Provinsi Sulawesi Selatan dijumpai di pantai barat, pantai selatan, dan pantai timur (Gambar 1). Sampai tahun 2005, luas tambak di pantai timur Provinsi Sulawesi Selatan mencapai 42.839 ha atau sekitar $44,64 \%$ dari luas total tambak di provinsi ini (Anonim, 2005). Tambak di pantai timur Sulawesi Selatan tersebut tersebar di Kabupaten Luwu Timur (Lutim), Luwu Utara (Lutra), Luwu, Wajo, Bone, dan Sinjai serta Kota Palopo dengan luas masing-masing berturut-turut 5.441 ha, 7.628 ha, 4.408 ha, 12.988 ha, 10.810 ha, 678 ha, dan 916 ha. Produktivitas tambak di pantai timur Provinsi Sulawesi Selatan masih tergolong rendah, terutama untuk udang windu (Penaeus monodon) dan ikan bandeng (Chanos chanos). Pantai timur Sulawesi Selatan juga masih memiliki potensial lahan seluas 15.000 ha untuk budidaya tambak (DKP, 2005). Dengan demikian, masih ada peluang peningkatan produksi budidaya tambak, baik melalui intensifikasi, ekstensifikasi, maupun diversifikasi.

Faktor lingkungan adalah faktor yang dipertimbangkan dalam usaha budidaya tambak, karena setiap komoditas menuntut faktor lingkungan yang dapat berbeda untuk tumbuh secara optimum. Faktor lingkungan dalam tambak yang sangat berpengaruh terhadap budidaya tambak adalah kualitas tanah dan kualitas air. Salah satu jenis tanah yang umum dijumpai di pantai timur Sulawesi Selatan adalah tanah sulfat masam. Tanah sulfat masam adalah tanah yang mengandung besi sulfida atau $\mathrm{FeS}_{2}$ (pirit) yang dicirikan dengan $\mathrm{pH}$ rendah dan ketersediaan unsur-unsur beracun yang tinggi, sehingga produktivitasnya relatif rendah. Kualitas tanah sulfat masam yang demikian akan mempengaruhi kualitas air pada tambaknya melalui proses kimia, fisika, dan biologi (Boyd, 1990).

Dalam Program Revitalisasi Pertanian, Perikanan, dan Kehutanan yang dicanangkan oleh Presiden Republik Indonesia pada tanggal 11 Juni 2005, rumput laut merupakan salah satu komoditas yang mendapatkan prioritas selain udang dan tuna (DKP, 2005). Budidaya 


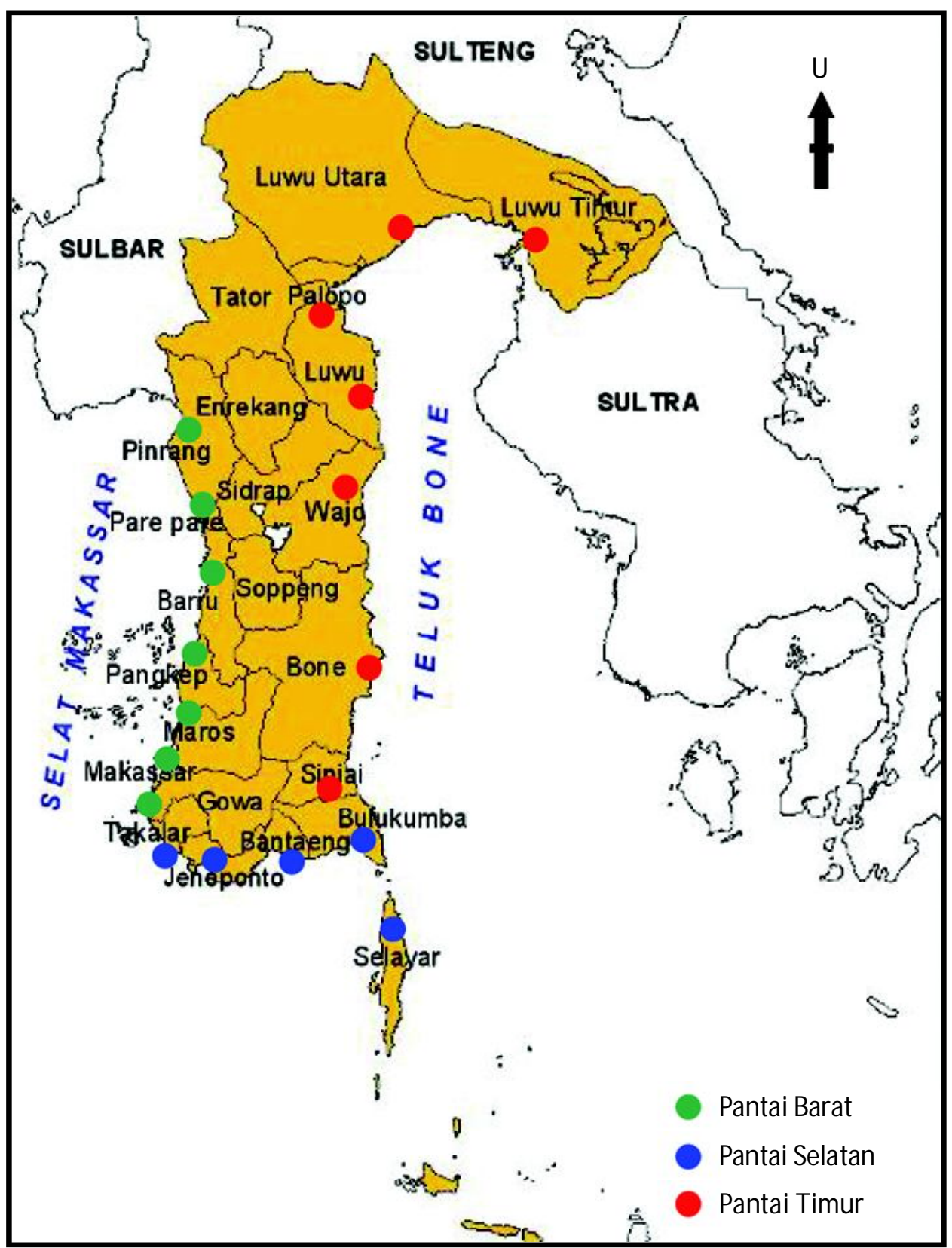

Gambar 1. Pembagian secara geografis dari setiap kabupaten yang memiliki lahan budidaya tambak di Provinsi Sulawesi Selatan

rumput laut adalah alternatif kegiatan yang berwawasan lingkungan dan produktif bagi penduduk di kawasan pesisir (Sukadi, 2006). Rumput laut (Gracilaria verrucosa) juga merupakan salah satu komoditas perikanan yang telah dibudidayakan di tambak termasuk tambak tanah sulfat masam di pantai timur Sulawesi Selatan. Tambak yang tidak lagi produktif untuk udang dan ikan dapat digunakan bagi usaha budidaya rumput laut, walaupun harus memenuhi persyaratan teknis dan biologis lain (Mubarak et al., 1990). Telah dilaporkan bahwa kualitas rumput laut dari bagian utara pantai timur Provinsi Sulawesi Selatan merupakan salah satu yang terbaik di Indonesia (Anonim, 2003).

Tulisan ini bertujuan untuk memberikan informasi mengenai faktor lingkungan yaitu kualitas tanah dan kualitas air di tambak tanah sulfat masam di pantai timur Sulawesi Selatan dengan harapan dapat dijadikan bahan pertimbangan teknis dalam budidaya rumput laut di tempat lain yang memiliki karakteristik lahan (tanah dan air) yang relatif sama. 


\section{PRODUKSI RUMPUT LAUT}

Kondisi tambak yang umum digunakan untuk budidaya rumput laut di pantai timur Provinsi Sulawesi Selatan terlihat pada Gambar 2. Produksi rumput laut di tambak pantai timur Sulawesi Selatan dapat dilihat pada Tabel 1. Rata-rata produksi rumput laut di Kabupaten Sinjai, Luwu, dan Lutra berturut-turut 5.753, 6.218, dan 7.821 kg kering/ ha/tahun. Di pantai barat Sulawesi Selatan yaitu di Kabupaten Maros, produksi rumput laut di tambak yang juga tergolong tanah sulfat masam yaitu 1.178 kg kering/ ha (Pantjara et al., 2008). Di tambak Kabupaten Takalar yang terletak di pantai selatan Sulawesi yang juga merupakan sentra produksi rumput laut, produksinya mencapai $3.097 \mathrm{~kg}$ kering/ha/musim (Retnowati et al., 1995).

Rumput laut dibudidayakan di tambak pantai timur Sulawesi Selatan melalui polikultur dengan bandeng. Padat penebaran nener bandeng yang diaplikasikan pembudidaya rata-rata 4.465 ekor/ha/tahun di Kabupaten Luwu (Mustafa \& Ratnawati, 2005) dan 2.484 ekor/ha/tahun di Kabupaten Lutra (Ratnawati et al., 2008). Namun demikian, informasi produksi bandeng tidak didapatkan sebab hanya untuk dikonsumsi sendiri. Kehadiran bandeng dalam polikultur dengan rumput laut diharapkan dapat membersihkan rumput laut yang ditempeli oleh klekap dan lumut dengan cara memakan klekap dan lumut tersebut. Dalam budidaya rumput laut biasanya ditebarkan bandeng dan udang yang dimaksudkan untuk mengurangi lumut di dalam tambak, karena keberadaan lumut akan menurunkan kualitas rumput laut kering (Retnowati et al., 1995). Bandeng akan

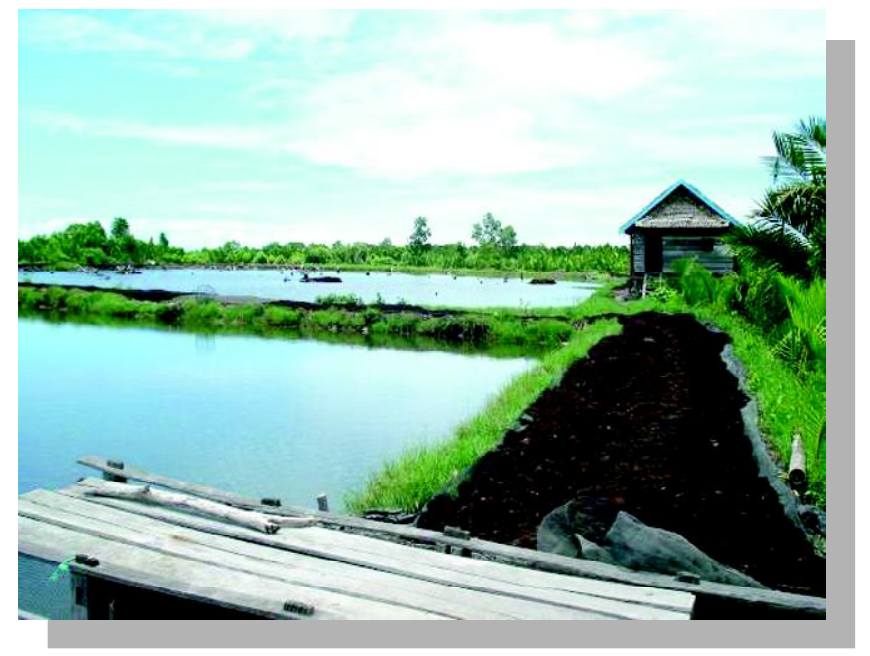

Gambar 2. Kondisi umum tambak tanah sulfat masam untuk budidaya rumput laut (Gracilaria verrucosa) di Kabupaten Luwu Utara, Provinsi Sulawesi Selatan
Tabel 1. Produksi rumput laut (Gracilaria verrucosa) di tambak pantai timur Sulawesi Selatan

\begin{tabular}{lcccc}
\hline \multirow{2}{*}{ Kabupaten } & \multicolumn{4}{c}{ Produksi (kg kering/ha/tahun) } \\
\cline { 2 - 5 } & Minimum & Maksimum & Rataan & $\begin{array}{c}\text { Simpangan } \\
\text { baku }\end{array}$ \\
\hline Sinjai $(n=11)$ & 1.002 & 15.000 & 5.753 & 3,793 \\
Luwu $(n=19)$ & 250 & 15.000 & 6.218 & 3,731 \\
Luwu Utara $(n=54)$ & 150 & 40.909 & 7.821 & 7,042 \\
\hline
\end{tabular}

memakan epifit yang menempel pada rumput laut dan akan meningkatkan kualitas rumput laut (Sammut et al., 2003). Selain itu, ikan bandeng diharapkan juga dapat menimbulkan gerakan air sehingga lumpur yang menempel pada rumput laut dapat terlepas. Akibat lebih lanjut adalah proses difusi unsur hara ke dalam rumput laut lebih meningkat, sehingga pertumbuhan rumput laut dapat lebih baik.

\section{LINGKUNGAN UNTUK RUMPUT LAUT}

Dua faktor lingkungan yang sangat besar pengaruhnya terhadap produktivitas tambak termasuk produksi rumput laut adalah kualitas tanah dan kualitas air. Karena rumput laut tidak memiliki bagian khusus yang dapat menyerap unsur hara, seperti akar pada tanaman secara umum, maka seluruh bagian tubuh rumput laut dapat menyerap unsur hara dari air. Kualitas air tambak dapat dipengaruhi oleh kualitas tanah dasar dan pematang tambak.

\section{Kualitas Tanah}

Derajat kemasaman atau $\mathrm{pH}$ tanah merupakan penciri utama tanah sulfat masam dan menggambarkan kondisi kemasaman, proses kimia yang mungkin terjadi serta akibatnya terhadap kualitas tanah. Baik $\mathrm{pH}_{\mathrm{F}}$ maupun $\mathrm{pH}_{\mathrm{Fox}}$ tanah memiliki hubungan yang sangat nyata terhadap produksi rumput laut di tambak, yaitu makin tinggi $\mathrm{pH}$ maka makin tinggi pula produksi rumput lautnya (Gambar 3). $\mathrm{pH}_{\mathrm{F}}$ adalah $\mathrm{pH}$ tanah yang diukur langsung di lapangan, sedangkan $\mathrm{pH}_{\mathrm{Fox}}$ adalah $\mathrm{pH}$ tanah yang diukur setelah tanah dioksidasi sempurna dengan $\mathrm{H}_{2} \mathrm{O}_{2}$ (hidrogen peroksida) $30 \%$ yang juga diukur di lapangan. Pengaruh keduanya terhadap produksi rumput laut juga relatif sama besarnya yaitu $\mathrm{pH}_{\mathrm{F}}$ berkontribusi sebesar $45,8 \%$ sedangkan $\mathrm{pH}_{\mathrm{FOX}}$ berkontribusi sebesar 46,0\%terhadap produksi rumput laut. Telah dilaporkan oleh Mustafa \& Sammut (2006), bahwa peningkatan 1 unit $\mathrm{pH}_{\mathrm{Fox}}$ sampai kondisi netral dapat meningkatkan produksi rumput laut 204 kg kering/ ha/tahun di Kabupaten Luwu. 
Selisih antara $\mathrm{pH}_{\mathrm{F}}$ dan $\mathrm{pH}_{\mathrm{FOX}}\left(\mathrm{pH}_{\mathrm{F}}-\mathrm{pH}_{\mathrm{FOX}}\right)$ dapat menggambarkan potensi kemasaman dari tanah sulfat masam. $\mathrm{pH}_{\mathrm{F}}-\mathrm{pH}_{\mathrm{Fox}}$ juga berhubungan secara sangat nyata di mana penurunan nilai $\mathrm{pH}_{\mathrm{F}}-\mathrm{pH}_{\mathrm{FOx}}$ diikuti dengan peningkatan produksi rumput laut. Dari hasil analisis peubah-peubah kualitas tanah yang menggambarkan kemasaman tanah menunjukkan bahwa rumput laut dapat
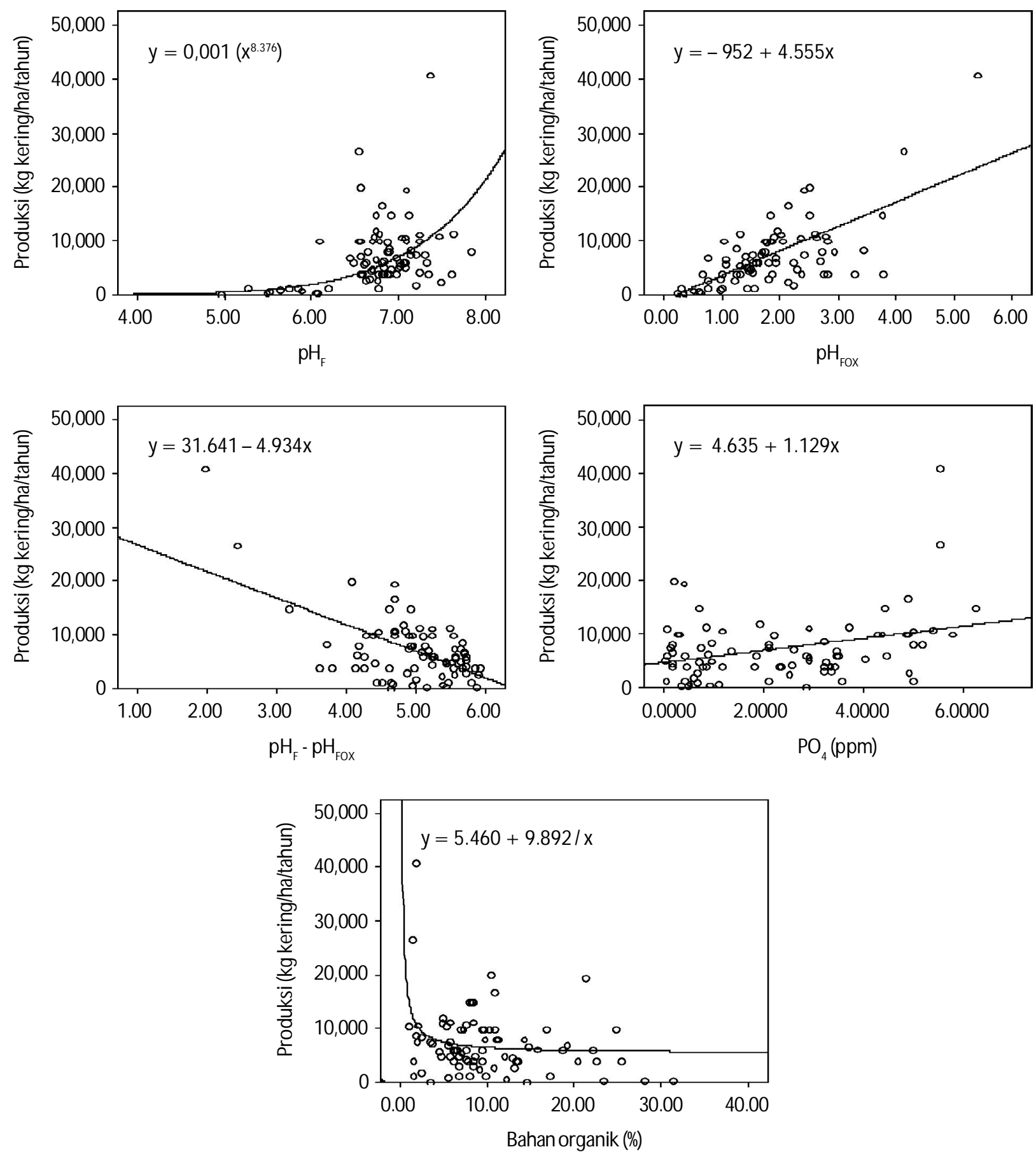

Gambar 3. Hubungan antara produksi rumput laut (Gracilaria verrucosa) dengan $\mathrm{pH}_{\mathrm{F}}, \mathrm{pH}_{\mathrm{FOX}}, \mathrm{pH}_{\mathrm{F}}-\mathrm{pH}_{\mathrm{FOX}}, \mathrm{PO}_{4^{\prime}}$ dan bahan organik tanah tambak di pantai timur Sulawesi Selatan (Sumber: Mustafa et al., 2008) 
Kandungan $\mathrm{PO}_{4}$ (fosfat) tanah sangat nyata pengaruhnya terhadap produksi rumput laut di tambak, di mana makin tinggi kandungan $\mathrm{PO}_{4}$ tanah maka semakin tinggi pula produksi rumput lautnya. Kandungan $\mathrm{PO}_{4}$ pada tanah sulfat masam umumnya sangat rendah sebab terikat oleh $\mathrm{Fe}$ (besi) dan Al (aluminium), sehingga menjadi tidak tersedia bagi organisme akuatik yang membutuhkannya. Selain itu, pembudidaya rumput laut seperti di Kabupaten Lutra dan Luwu memberikan pupuk yang mengandung fosfat dalam dosis yang kecil. Padahal, P (fosfor) merupakan unsur penting bagi semua aspek kehidupan terutama untuk transformasi energi metabolik.

Telah disebutkan sebelumnya bahwa tambak yang digunakan untuk budidaya rumput laut di pantai timur Sulawesi Selatan umumnya didominasi oleh tanah sulfat masam. Tanah sulfat masam ini biasanya berasosiasi dengan tanah gambut sehingga kandungan bahan organik tanah dapat mencapai 31,4\%dengan rata-rata 9,8\% Bahan organik yang telah terdekomposisi dapat menjadi sumber hara bagi rumput laut, namun demikian jika kandungannya terlalu tinggi dapat menghambat pertumbuhan. Juga telah disebutkan sebelumnya bahwa dekomposisi bahan organik dapat menghasilkan $\mathrm{CO}_{2}$ (karbon dioksida), $\mathrm{H}_{2} \mathrm{~S}$ (hidrogen sulfida), dan $\mathrm{CH}_{4}$ (metan) yang tinggi juga dapat menghambat pertumbuhan organisme akuatik.

Besi dan Al adalah logam yang biasa melimpah di tanah sulfat masam. Kandungan Fe tanah berkorelasi secara nyata dan pada kandungan lebih besar dari $5.000 \mathrm{mg} / \mathrm{L}$ berdampak pada penurunan produksi rumput laut (Gambar 4). Besi dibutuhkan oleh tanaman termasuk rumput laut sebagai penyusun sitokrom dan klorofil serta berperan dalam sistem enzim dan transfer elektron pada proses fotosintesis (Effendi, 2003). Besi juga merupakan logam yang dibutuhkan oleh alga paling besar dibandingkan dengan logam lainnya (Malea \& Haritinodis, 1999; Caliceti et al., 2002). Namun demikian, kelebihan Fe tanah berdampak pada pengikatan senyawa tertentu seperti fosfat menjadi tidak tersedia bagi rumput laut. Mustafa \& Sammut (2007) telah melaporkan adanya korelasi yang sangat nyata antara kandungan Fe dan P-tersedia di mana makin tinggi kandungan Fe maka kandungan P-tersedia makin kecil. Selain itu, kelebihan Fe dapat menyebabkan keracunan pada tanaman seperti pada tanaman padi, sekalipun tergolong tahan terhadap kondisi kandungan Fetinggi, sebagian mengalami keracunan pada kandungan Fe 500 mg/L (Ponnamperuma, 1976).

Kandungan Al berhubungan tidak nyata dengan produksi rumput laut di tambak. Dalam hal ini, kandungan Al antara 96 dan 1.195 mg/L belum memberikan pengaruh terhadap produksi rumput laut. Namun demikian, ada kecenderungan penurunan produksi rumput laut pada tanah dengan kandungan Al melebihi 490 mg/L (Gambar 4). Kelarutan Al yang tinggi menyebabkan pembelahan dan perkembangan sel terhambat akibat enzim yang melakukan sintesis bahan dari dinding sel terganggu (Rorison, 1973).

Pada tanah sulfat masam maupun tanah sulfat masam yang berasosiasi dengan tanah gambut menunjukkan kandungan liat yang sangat rendah bahkan beberapa contoh tanah tidak terdeteksi kandungan liatnya. Kandungan pasir sangat nyata pengaruhnya terhadap produksi rumput laut di mana makin rendah kandungan pasir makin tinggi produksi rumput laut. Hal ini sangat terkait dengan sifat fisik dan kimia dari fraksi pasir. Tambak dengan kandungan pasir yang tinggi berdampak pada tingginya porositas pematang yang menyebabkan tinggi air tambak tidak bisa bertahan. Dikatakan oleh Mubarak et al. (1990) bahwa lahan untuk budidaya rumput laut di tambak sebaiknya mempunyai dasar tambak yang bertekstur lempung berpasir, apabila dasar tambaknya memiliki porositas tinggi maka sangat sulit mempertahankan kedalaman air. Ada kemungkinan rendahnya tinggi air pada tambak yang didominasi fraksi pasir berdampak pada rendahnya produksi rumput laut. Telah direkomendasikan seperti disebutkan sebelumnya bahwa tinggi air untuk budidaya rumput laut adalah 0,6-0,8 m.

Sifat kimia dari fraksi pasir adalah kekurangmampuannya dalam menyerap air, ion-ion anorganik, bahan organik, dan gas-gas pada permukaannya. Sebagai akibatnya, tanah yang didominasi fraksi pasir kandungan haranya cenderung lebih rendah yang berdampak rendahnya produksi rumput laut. Tanah dengan kandungan fraksi pasir tinggi juga cenderung memiliki daya sangga yang rendah sehingga fluktuasi $\mathrm{pH}$ dapat lebih besar yang dapat pula mengganggu pertumbuhan rumput laut.

Kebalikan dari pengaruh fraksi pasir terhadap produksi rumput laut adalah adanya pengaruh secara sangat nyata yaitu dengan meningkatnya kandungan debu yang menyebabkan peningkatan produksi rumput laut. Secara fisik, kandungan debu yang lebih tinggi berdampak pada lebih kompaknya dasar tambak maupun pematang tambak sehingga kedalaman air dapat dipertahankan. Secara kimia, adanya kandungan fraksi debu, dan liat sampai nilai tertentu menunjukkan kondisi tanah yang lebih baik. Menurut Schaetzl \& Anderson (2005), debu memiliki kemampuan menyimpan unsur hara yang tergolong rendah dan liat tergolong sedang sampai tinggi, sedangkan pasir tergolong sangat rendah. Tanah bertekstur liat atau debu, karena lebih halus maka setiap satuan berat mempunyai 

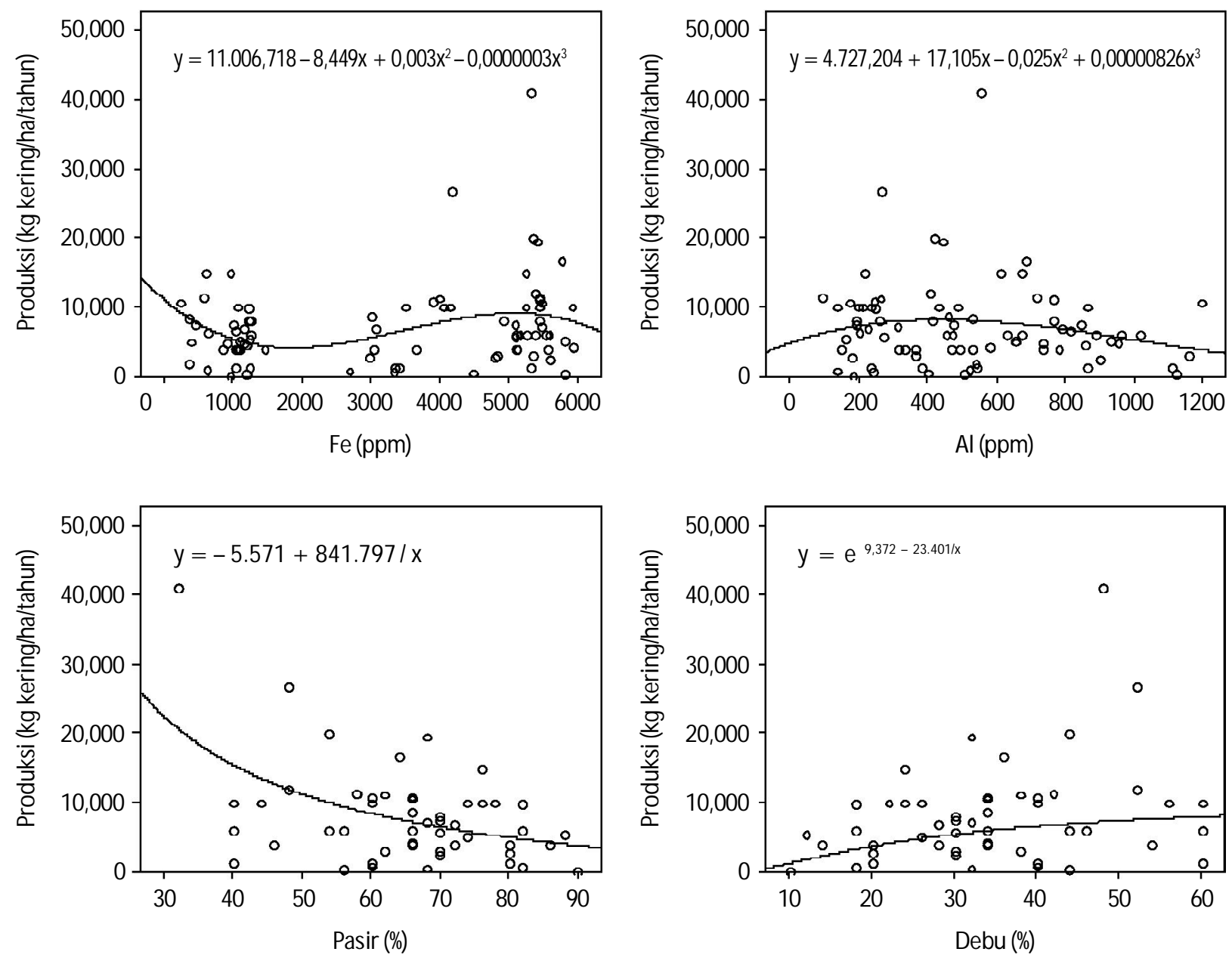

Gambar 4. Hubungan antara produksi rumput laut (Gracilaria verrucosa) dengan Fe, Al, pasir, dan debu dari tanah tambak di pantai timur Sulawesi Selatan (Sumber: Mustafa et al., 2008)

luas permukaan yang lebih besar sehingga kemampuan menahan air dan menyimpan unsur hara lebih tinggi. Dalam hal ini, ketersediaan unsur hara bagi rumput laut lebih terjamin pada tanah dengan kandungan debu dan liat tinggi dibandingkan dengan tanah dengan kandungan pasir tinggi sehingga pertumbuhan rumput laut dapat lebih baik.

\section{Kualitas Air}

Hubungan antara produksi rumput laut dengan berbagai peubah kualitas air di tambak pantai timur Sulawesi Selatan terlihat pada Gambar 5. Produksi rumput laut tertinggi didapatkan pada salinitas 25,6 ppt. Seperti dilaporkan oleh Tseng \& Borowitzka (2003) sebelumnya bahwa rumput laut tumbuh paling cepat pada salinitas 25 ppt dan Mubarak et al. (1990) menyatakan bahwa rumput laut tumbuh baik pada salinitas antara 18 dan 30 ppt. Tseng \& Borowitzka (2003) menyatakan bahwa rumput laut mulai mati pada salinitas lebih dari 35 ppt. Oleh karena itu, sumber air tawar dan air laut di tambak menjadi penting agar salinitas optimum dapat dipenuhi.

Suhu air tambak di pantai timur Sulawesi Selatan berkisar $26,0^{\circ} \mathrm{C}$ dan $37,9^{\circ} \mathrm{C}$ dengan rata-rata $31,7^{\circ} \mathrm{C}$. Diduga kisaran suhu air tambak tersebut belum nyata mempengaruhi produksi rumput laut. Suhu air $25^{\circ} \mathrm{C}-30^{\circ} \mathrm{C}$ adalah suhu yang baik untuk budidaya rumput laut (Hurtado-Ponce \& Umezaki, 1987). Sebaiknya, suhu air untuk budidaya rumput laut antara $20^{\circ} \mathrm{C}$ dan $28^{\circ} \mathrm{C}$ dengan fluktuasi harian maksimum $4^{\circ} \mathrm{C}$ (Mubarak et al., 1990).

Potensi kemasaman tanah yang cukup bervariasi besarnya berdampak pula pada pH air tambak yang cukup bervariasi. Sebagai akibatnya $\mathrm{pH}$ air berkontribusi sangat nyata terhadap produksi rumput laut, di mana $21,0 \%$ produksi rumput laut ditentukan oleh $\mathrm{pH}$ air. Rumput laut dapat tumbuh baik pada kisaran $\mathrm{pH}$ air yang lebar dari 6,0 sampai 9,3 di pantai timur Sulawesi Selatan. Telah dilaporkan bahwa pada pH kurang dari 4,0 sebagian 

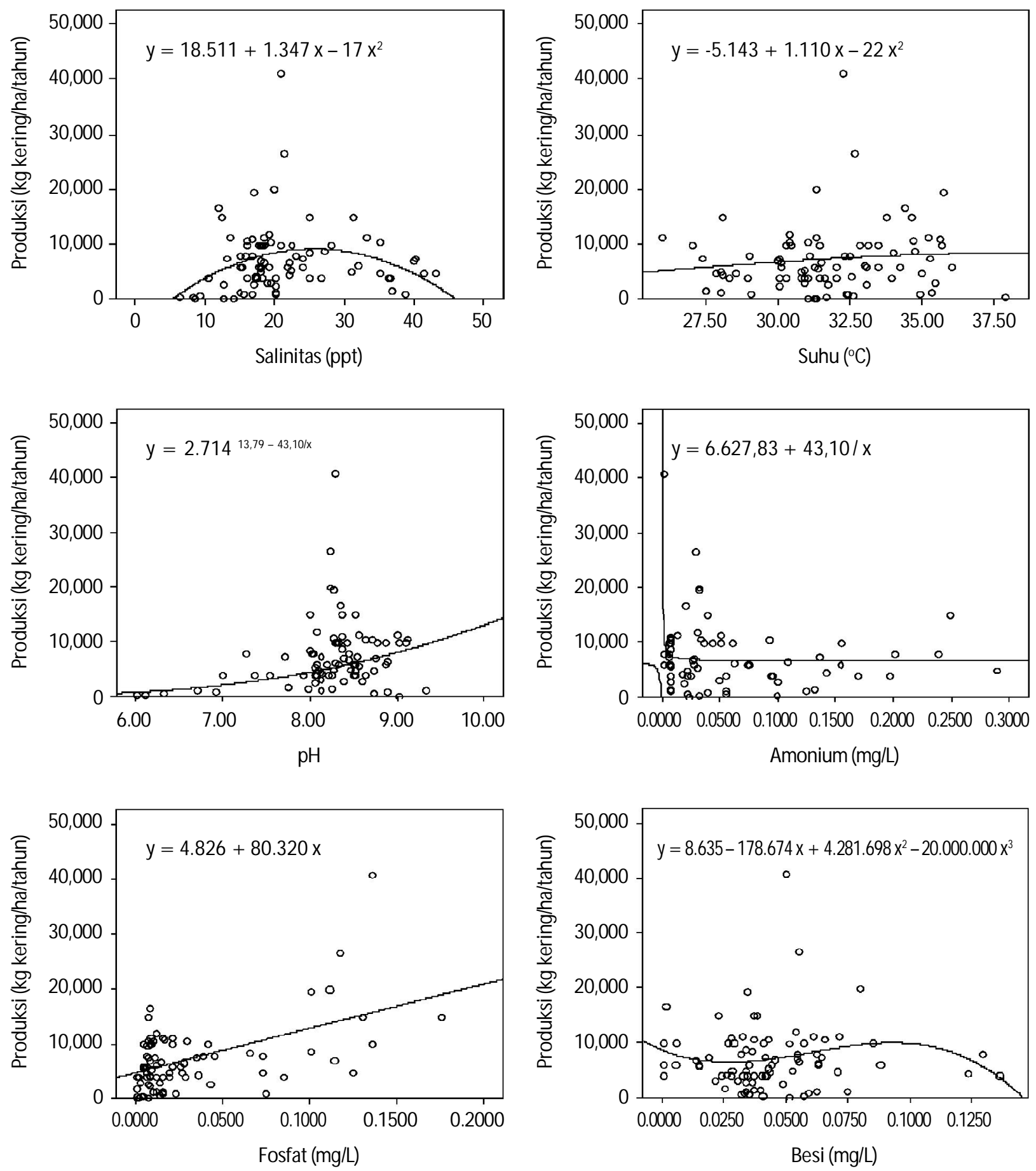

Gambar 5. Hubungan antara produksi rumput laut (Gracilaria verrucosa) dengan salinitas, suhu, pH, amonium, fosfat, dan besi air tambak di pantai timur Sulawesi Selatan (Sumber: Mustafa et al., 2007)

tumbuhan air mati karena tidak dapat bertoleransi lagi (Effendi, 2003).

Unsur hara merupakan salah satu faktor yang mempengaruhi pertumbuhan rumput laut. Unsur hara seperti $\mathrm{N}$ (nitrogen) dapat diserap oleh rumput laut dalam bentuk $\mathrm{NH}_{4}$ (amonium) dan $\mathrm{NO}_{3}$ (nitrat), di mana $\mathrm{NH}_{4}$ lebih disukai daripada $\mathrm{NO}_{3}$ (Yang et al., 2006). Terdapat hubungan sangat nyata antara kandungan $\mathrm{NH}_{4}$ dan produksi rumput laut yang menunjukkan makin rendah kandungan $\mathrm{NH}_{4}$ dalam air maka produksi rumput laut lebih tinggi. Telah dilaporkan sebelumnya oleh Mustafa \& Ratnawati (2005) serta Mustafa \& Sammut (2006) bahwa 
penambahan dosis pupuk yang mengandung $\mathrm{N}$ pada tambak untuk budidaya rumput laut di Kabupaten Luwu, Sulawesi Selatan dapat menurunkan produksi rumput laut. Ada dugaan, kandungan $\mathrm{N}$ baik di tanah maupun di air tambak sudah tergolong tinggi sebagai akibat pemberian pupuk yang mengandung $\mathrm{N}$ yang juga tinggi di pantai timur Sulawesi Selatan.

Selain N, unsur hara lain yang diperlukan oleh rumput laut adalah P. Fosfor merupakan unsur yang esensial bagi tumbuhan tingkat tinggi dan alga akuatik, sehingga unsur ini menjadi faktor pembatas bagi tumbuhan dan alga akuatik serta sangat mempengaruhi tingkat produktivitas perairan. Kandungan $\mathrm{PO}_{4}$ air tambak untuk budidaya rumput laut rata-rata $0,0303 \mathrm{mg} / \mathrm{L}$ dan digolongkan perairan dengan tingkat kesuburan sedang (Liaw, 1969). Dengan demikian, peningkatan kandungan $\mathrm{PO}_{4}$ dapat meningkatkan produksi rumput laut. Selain itu, dikenal pula istilah "konsumsi lebih" pada alga akuatik yaitu pada saat perairan cukup mengandung $P$, alga akuatik mengakumulasi $P$ di dalam sel melebihi kebutuhannya (Boney, 1989). Kelebihan P yang diserap akan dimanfaatkan pada saat perairan kekurangan $P$, sehingga rumput laut masih dapat tumbuh selama beberapa waktu selama periode kekurangan pasokan $\mathrm{P}$.

Besi termasuk unsur yang esensial bagi makhluk hidup. Pada tumbuhan, termasuk rumput laut, Fe berperan sebagai penyusun sitokrom dan klorofil serta berperan dalam sistem enzim dan transfer elektron pada proses fotosintesis. Kisaran kandungan Fe air tambak di pantai timur Sulawesi Selatan untuk budidaya rumput laut dari 0,0004 sampai $0,1359 \mathrm{mg} / \mathrm{L}$ dengan rata-rata 0,0433 $\mathrm{mg} / \mathrm{L}$, masih dalam kisaran yang bisa ditolerir oleh organisme akuatik sehingga tidak memberikan pengaruh yang nyata terhadap produksi rumput laut. Dikatakan oleh Boyd (1990), kandungan Fe pada perairan alami berkisar antara 0,05 dan 0,20 mg/L. Kandungan Fe air yang lebih tinggi dari 1,0 mg/L dianggap membahayakan kehidupan organisme akuatik (Moore, 1991). Selain itu, tanaman air dan alga mempunyai kemampuan untuk menyerap logam seperti Fe dan Al. Lebih lanjut Gosavi et al. (2004) menyatakan bahwa alga dapat menyerap Fe dan Al tiga kali lipat dibandingkan terhadap logam lainnya. Tanaman air dan alga memiliki toleransi yang lebih tinggi dibandingkan dengan ikan dan udang terhadap keberadaan logam (Effendi, 2003).

\section{KESIMPULAN}

Produktivitas tambak untuk rumput laut (Gracilaria verrucosa) di pantai timur Sulawesi Selatan berkisar antara 150 sampai 40.909 dengan rata-rata 7.187 kg kering/ha/ tahun. Produktivitas tambak tanah sulfat masam yang tinggi untuk rumput laut di pantai timur Provinsi Sulawesi Selatan didapatkan pada tanah dengan $\mathrm{pH}_{\mathrm{F}}$ lebih besar 6,5, $\mathrm{pH}_{\mathrm{FOX}}$ lebih besar 4,0, $\mathrm{pH}_{\mathrm{F}}-\mathrm{pH}_{\mathrm{FOX}}$ kurang dari 2,5 dan $\mathrm{S}_{\mathrm{POS}}$ kurang dari 1,00\% Kandungan Fe tanah yang melebihi $5.000 \mathrm{mg} / \mathrm{L}$ dan Al yang melebihi $490 \mathrm{mg} / \mathrm{L}$ menyebabkan penurunan produktivitas tambak untuk rumput laut. Peningkatan kandungan $\mathrm{PO}_{4}$ tanah lebih besar dari 6,0 $\mathrm{mg} / \mathrm{L}$ dapat meningkatkan produktivitas tambak untuk budidaya rumput laut secara nyata.

Produktivitas tambak untuk rumput laut tertinggi didapatkan pada salinitas 25,6 ppt dan oksigen terlarut $8,39 \mathrm{mg} / \mathrm{L}$ dan rumput laut masih tumbuh baik pada kisaran pH antara 6,00 dan 9,32 ; suhu antara $26,00^{\circ} \mathrm{C}$ dan $37,86^{\circ} \mathrm{C}$; fosfat lebih besar $0,1000 \mathrm{mg} / \mathrm{L}$; dan besi kurang dari $0,1000 \mathrm{mg} / \mathrm{L}$ di tambak tanah sulfat masam pantai timur Provinsi Sulawesi Selatan.

\section{DAFTAR ACUAN}

Anonim. 2003. Rumput laut Luwu terbaik di Indonesia. Fajar, Senin, 17 Maret 2003, hlm. 16.

Anonim. 2005. Laporan Statistik Perikanan Sulawesi Selatan. Dinas Perikanan dan Kelautan Provinsi Sulawesi Selatan, Makassar, $261 \mathrm{hlm}$.

Boney, A.D. 1989. Phytoplankton. Second edition. Edward Arnold, London, $118 \mathrm{pp}$.

Boyd, C.E. 1990. Water Quality in Ponds for Aquaculture. Birmingham Publishing Co., Birmingham, Alabama, 454 pp.

Caliceti, M., Argese, E., Sfriso, A., \& Pavoni, B. 2002. Heavy metal contamination in the seaweeds of the Venice lagoon. Chemosphere, 47: 443-454.

Departemen Kelautan dan Perikanan (DKP). 2005. Revitalisasi Perikanan Budidaya. Departemen Kelautan dan Perikanan, Jakarta, $275 \mathrm{hlm}$.

Effendi, H. 2003. Telaah KualitasAir bagi Pengelolaan Sumber Daya dan Lingkungan Perairan. Penerbit Kanisius, Yogyakarta, $258 \mathrm{hlm}$.

Gosavi, K., Sammut, J., Gifford, S., \& Jankowski, J. 2004. Macroalgal biomonitors of trace metal contamination in acid sulfate soil aquaculture ponds. Science of the Total Environment, 324(1-3): 25-39.

Hurtado-Ponce, A.Q. \& Umezaki, I. 1987. Growth rate studies of Gracilaria verrucosa (Gigartinales, Rhodophyta). Botanica Marina, 30: 223-226.

Liaw, W.K. 1969. Chemical and biological studies of fishponds and reservoirs in Taiwan. Rep. Fish Culture Res., Fish. Series, Chin. Am. Joint Commission on Rural Reconstruction, 7: 1-43. 
Malea, P. \& Haritonidis, S. 1999. Metal content in Enteromorpha linza (Linnaeus) in Themaikos Gulf (Greece). Hydrobiologia, 394: 103-112.

Moore, J.W. 1991. Inorganic Contaminants of Surface Water. Springer-Verlag, New York, 334 pp.

Mubarak, H., Ilyas, S, Ismail, W., Wahyuni, I.S., Hartati, S.T., Pratiwi, E., Jangkaru, Z., \& Arifudin, R. 1990. Petunjuk Teknis Budidaya Rumput Laut. Pusat Penelitian dan Pengembangan Perikanan, Jakarta, $93 \mathrm{hlm}$.

Mustafa, A., Paena, M., Tarunamulia, \& Sammut, J. 2008. Hubungan antara faktor lingkungan dan produktivitas tambak untuk penajaman kriteria kesesuaian lahan: 2. kualitas tanah. J. Ris. Akuakultur, 3(1): 105-121.

Mustafa, A. \& Ratnawati, E. 2005. Faktor pengelolaan yang berpengaruh terhadap produksi rumput laut (Gracilaria verrucosa) di tambak tanah sulfat masam (studi kasus di Kabupaten Luwu, Provinsi Sulawesi Selatan). J. Pen. Perik. Indonesia, 11(7): 67-77.

Mustafa, A. \& Sammut, J. 2006. Dominant Factors that Effect on the Seaweed (Gracilaria verrucosa) Production in Acid Sulfate Soils-affected Ponds of Luwu Regency, Indonesia. Research Institute for Coastal Aquaculture, Maros, 28 pp.

Mustafa, A. \& Sammut, J. 2007. Effect of different remediation techniques and dosages of phosphorus fertilizer on soil quality and klekap production in acid sulfate soil affected aquaculture ponds. Indonesian Aquaculture J., 2(2): 141-157.

Mustafa, A., Sapo, I., Hasnawi, \& Sammut, J. 2007. Hubungan antara faktor lingkungan dan produktivitas tambak untuk penajaman kriteria kelayakan lahan: 1. kualitas air. J. Ris. Akuakultur 2(3): 289-302.

Pantjara, B., Tahu, S., Mustafa, A., \& Hendradjat, E.A. 2008. Pemanfaatan tambak marginal tanah sulfat masam untuk budidaya bandeng Chanos chanos, nila merah Oreochromis niloticus dan rumput laut Gracilaria verrucosa. Dalam: Said, I., Binaradja, G., Musyafik, A., Yaniharto, D., \& Sudaryanto, A. (Eds.), Prosiding Konferensi Aquaculture Indonesia 2008. Badan Penerbit Universitas Diponegoro, Semarang, hlm. 295-302.

Ponnamperuma, F.N. 1976. Spesific Soil Chemical Characteristics for Rice Production in Asia. IRRI Research Paper Seri No. 2. The International Rice Research Institute, Los Baòos, 18 pp.
Ratnawati, E., M ustafa, A. dan Rachmansyah. 2008. Faktor status pembudidaya, kondisi dan pengelolaan tambak yang berpengaruh terhadap produksi rumput laut (Gracilaria verrucosa) di tambak tanah sulfat masam Kabupaten Luwu Utara Provinsi Sulawesi Selatan. Jurnal Riset Akuakultur 3(2), 275-287.

Retnowati, N., J.T. Murtini, S. W ibowo, \& Suparno. 1995. Kajian pemasaran dalam menunjang usaha budidaya rumput laut. Dalam: Cholik, F., Rukyani, A., Sarnita, A.S., Heruwati, E.S., Suparno, Monintja, D., Soewardi, K., Widodo, J., \& Nikijuluw, V.P. (Eds.). Prosiding Simposium Perikanan Indonesia I, Buku II Bidang: Pascapanen, Sosial Ekonomi, dan Penangkapan. Pusat Penelitian dan Pengembangan Perikanan, Jakarta, hlm. 289-302.

Rorison, I.H. 1973. The effect of extreme soil acidity on the nutrient uptake and physiology of plant. In: Dost, $\mathrm{H}$. (Ed.), Proceedings of the International Symposium on Acid Sulphate Soils. ILRI Publication 18. International Institute for Land Reclamation and Improvement, Wageningen, p. 223-254.

Sammut, J., Mustafa, A., Hanafi, A., Tarunamulia, \& Tahe, S. 2003. Polyculture: extends production life for ponds with acid sulfate soil. Global AquacultureAdvocate, June 2003, 6(3): 72-73.

Schaetzl, R.J., \& Anderson, S. 2005. Soils: Genesis and Geomorphology. Cambridge University Press, Cambridge, $817 \mathrm{pp}$.

Sukadi, M.F. 2006. Perkembangan budidaya rumput laut di Indonesia. Dalam: Cholik, F., Moeslim, S., Heruwati, E.S., Ahmad, T., \& Jauzi, A. (Eds.), 60 tahun Perikanan Indonesia. Masyarakat Perikanan Nusantara, Jakarta, hlm. 213-223.

Tseng, C.K. \& Borowitzka, M. 2003. Algae culture. In: Lucas, J.S., \& Southgate, P.C. (Eds.), Aquaculture: Farming Aquatic Animals and Plants. Blackwell Publishing Ltd., Oxford, p. 253-275.

Yang, Y.-F., Fei, X.-G., Song, J.-M, Hu, H.-Y., Wang, G.C., \& Chung, I.K. 2006. Growth of Gracilaria lemaneiformis under different cultivation conditions and its effects on nutrient removal in Chinese coastal waters. Aquaculture, 254: 248-255. 